\title{
Understanding the Implications of a Shifting Opioid Landscape in Ontario
}

Tara Gomes and David N. Juurlink

\begin{abstract}
North America is currently in the midst of an opioid overdose crisis, leading to changes in drug policy and clinical practice guideline recommendations. Data from Ontario's prescription monitoring program and the Office of the Chief Coroner for Ontario can be used to characterize changing prescription opioid trends and their role in fatal opioid overdoses. A better understanding of historical patterns of opioid use and overdose can help inform a more nuanced drug policy in the future.
\end{abstract}

\section{The Issue}

Opioid-related harm has emerged as one of the most pressing public health issues of our time. In 2018, more than 12 people died from an opioid overdose every day in Canada (Special Advisory Committee on the Epidemic of Opioid Overdoses 2019), and one in six deaths among young adults is now attributable to opioids (Gomes et al. 2018a). Importantly, the negative effects of opioids have been experienced across all sociodemographic profiles (Public Health Ontario 2019); consequently, life expectancy at birth in Canada failed to increase between 2016 and 2017 for the first time in more than four decades (Statistics Canada 2019).

A large body of research has described the changing patterns of opioid prescribing and overdose across North America, with opioid-related harms initially attributed to the prescribing of opioids, particularly at high doses (Bohnert et al. 2011; Gomes et al. 2011; Park et al. 2015; Vowles et al. 2015). This practice was promoted by the successful, and sometimes illegal (Meier 2007), marketing of prescription opioids, together with inadequate pain management education among health professionals (Persaud 2014; U.S. Food and Drug Administration 2007; Van Zee 2009).Rising prescription rates catalyzed an iatrogenic increase in fatal opioid overdoses, with a 2009 study demonstrating that the introduction of long-acting oxycodone to the public drug formulary was associated with a fivefold increase in oxycodone-related mortality in Ontario (Dhalla et al. 2009).
As rates of opioid prescribing and related harm have risen across North America, the policy response has largely focused on the goal of promoting appropriate, judicious opioid prescribing aligned with emerging evidence. This has included the introduction of prescription monitoring programs (Furlan et al. 2014; Ontario Ministry of Health and Long-Term Care 2017), changing access to opioid formulations through public drug programs (Dyer 2016; Ontario College of Pharmacists 2016), labelling changes (Government of Canada 2018) and developing clinical guidelines (Busse et al. 2017; Dowell et al. 2016). However, the interrelationship between the prescribed and the non-prescribed opioid environment and changing drug policies have introduced considerable complexity to this issue. A better understanding of some of the implications of shifting opioid accessibility may help inform future policy decisions across North America.

\section{Changing Patterns of Opioid Prescribing in Ontario}

Prior to the introduction of OxyContin, a long-acting formulation of oxycodone, to the Ontario public drug formulary in 2000, the rate of opioid prescribing across the province was fairly consistent and dominated by prescriptions for codeine (Dhalla et al. 2009). However, following the expanded availability of OxyContin in Ontario and its marketing as a safe opioid with minimal potential for harm, there was an immediate increase in opioid prescribing driven by expansion of oxycodone use (Dhalla et al. 2009). This trend continued until 2012, when OxyContin was reformulated in Canada and replaced by a tamper-resistant formulation (OxyNEO). Although OxyContin had previously been listed on provincial formularies across Canada, most provinces opted for more restrictive reimbursement of OxyNEO, resulting in shifts in the types of opioids dispensed to patients eligible for public drug benefits (Gomes et al. 2017b). Furthermore, although generic forms of long-acting oxycodone were eventually approved by Health Canada (Miller 2013), these forms were not listed on most public drug plans because they were not tamper-deterrent, and there was concern that the long-acting properties of these 
products could be circumvented by crushing them, releasing all their contents at once. The net effect of these changes was a substantial reduction in the availability of long-acting oxycodone across Canada (Gomes et al. 2018b).

As long-acting oxycodone became less accessible, two key changes were observed in opioid prescribing patterns. First, overall prescribing of long-acting opioids declined by $23 \%$ in Ontario (from 50,865 to 39,288 milligrams of morphine or equivalent [MME] per 1,000 population) between February 2012 and April 2016 (Gomes et al. 2017b), and a 22\% reduction was observed in the annual rate of long-acting opioid recipients between 2013 and 2018 (from 14.1 to 10.9 recipients per 1,000 population; Figure 1). Second, prescribing shifted to strong opioids with fewer reimbursement constraints. Specifically, the annual number of hydromorphone recipients increased by $20 \%$ (from 60,779 to 72,971) between 2013 and 2016 as the annual number of oxycodone recipients declined (Figure 1). These shifts were expected as physicians and patients attempted to find alternatives to long-acting oxycodone for pain management. In subsequent years, additional policies have been implemented to regulate opioid availability, including the fentanyl patch-forpatch program in 2016 (Government of Ontario 2015; Ontario College of Pharmacists 2016) and the delisting of high-strength opioid formulations from the Ontario public drug formulary in 2017 (Dyer 2016). The impacts of these changes on prescribing trends are also evident in recent years as the number of recipients of these medications has declined (Figure 1).

\section{Impacts on Opioid-Related Deaths}

Although reducing opioid-related harms is the principal goal of a policy aimed at regulating opioid prescribing, reductions in opioid-related deaths have not been realized despite lower prescribing rates. Indeed, the opposite has occurred, with fatal overdose rates more than doubling since the delisting of OxyContin in 2012 (Figure 2). This reflects the multiple mechanisms that have contributed to fatal opioid overdoses over time and the limitations of policies that disrupt only the availability of prescribed opioids without considering social and structural drivers of these events.

Understanding the drivers of this divergence in rates of opioid prescribing and opioid-related harm requires a more detailed study of the specific opioids implicated in these deaths. Specifically, prior to 2012, oxycodone involvement in deaths increased in parallel with oxycodone prescribing, thereby supporting the notion that reduced oxycodone prescribing might similarly impact fatal opioid overdose rates. Although oxycodone involvement in opioid-related deaths declined following the implementation of policy limiting its access in 2012, deaths involving hydromorphone increased thereafter as prescribing shifted toward this drug, such that there was no net change in the provincial fatal opioid overdose rate (Figure 2). Moreover, as overall rates of long-acting opioid recipients began to fall in 2015, the rate of fatal opioid overdoses increased by $87 \%$ over just three years (5.3 to 9.9 deaths per 100,000 population from 2015 to 2018; Figure 2).

\section{FIGURE 1.}

Trends in long-acting prescription opioid dispensing in Ontario, 2013-2018

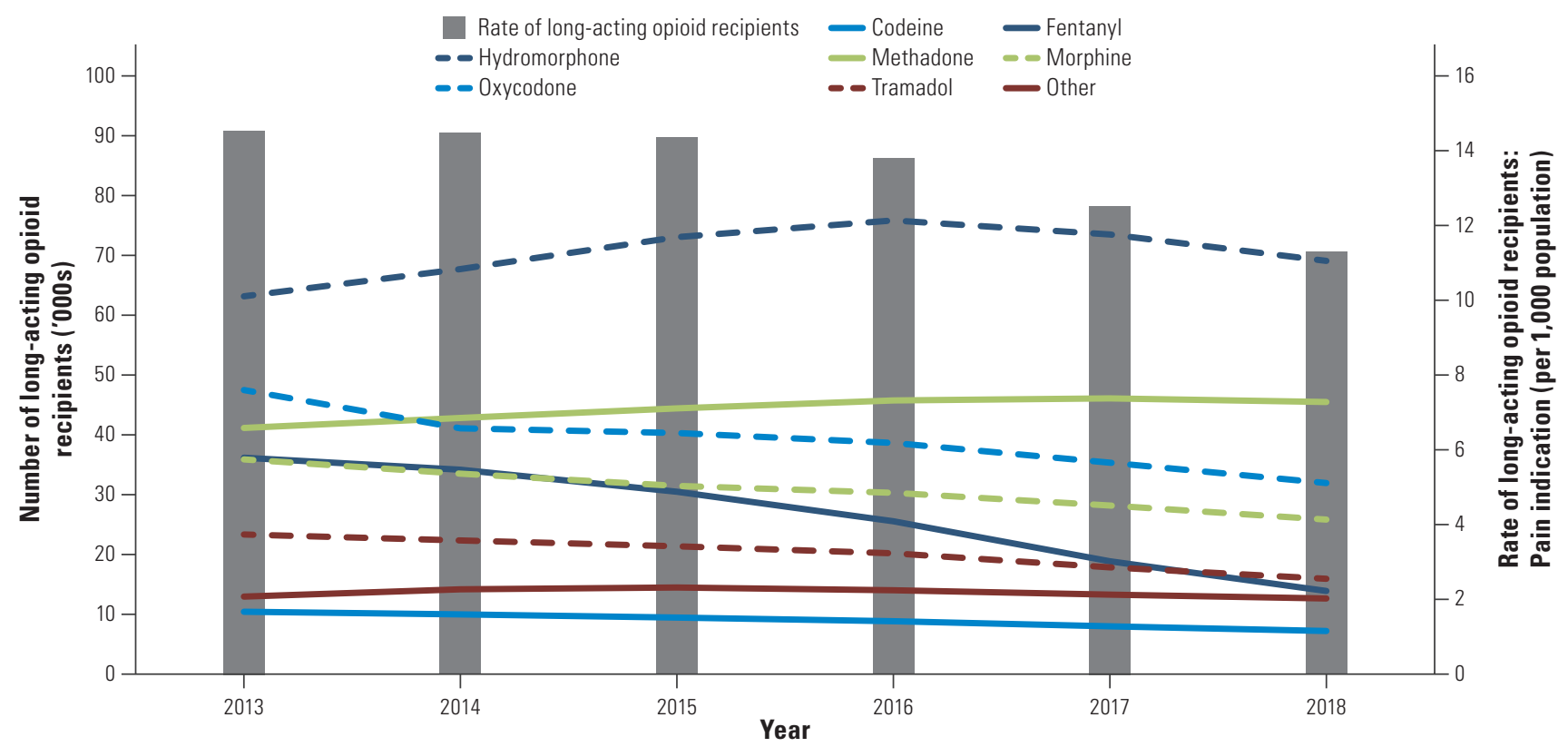


FIGURE 2.

Rate of opioid-related deaths in Ontario and specific drug involvement, 1991-2018

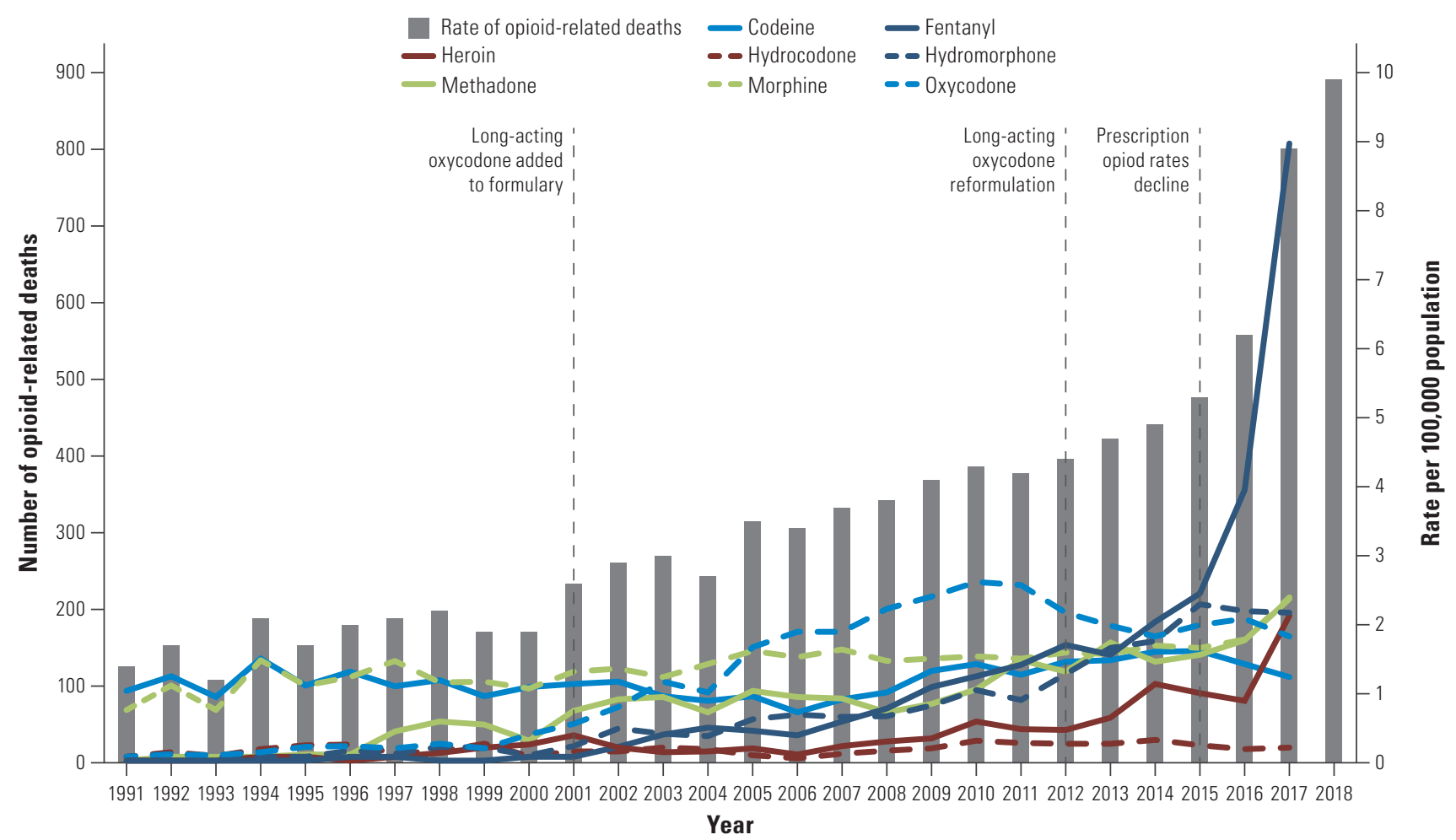

Note: Data on drug involvement in death were not available in 2018

Sources: Gomes et al. 2017a; Public Health Ontario 2019.

This trend was driven by non-prescribed opioids, with heroin-related deaths more than doubling (88 to 189 deaths) and fentanyl-related deaths almost quadrupling (218 to 805 deaths) between 2015 and 2017 (Figure 2). More recently, although prescription opioids continue to be involved in up to one quarter of accidental opioid-related deaths in Ontario, synthetic, non-prescribed opioids account for an increasing proportion of these events, with fentanyl and fentanyl analogues involved in nearly three-quarters of opioid-related deaths between July 2017 and June 2018 (Public Health Ontario et al. 2019).

Overall, these findings demonstrate that although policies aimed at preventing initial exposure to opioids may prevent downstream harm over the long term, these are unlikely to directly affect rates of fatal overdoses, and these policies have the unintended consequence of increasing the number of overdoses by limiting access to a safer supply of opioids. Learning from, and anticipating, unintended consequences is therefore an important prerequisite to formulating future policy that is intended to promote the safe use of opioids and improve the lives of people who take these drugs, including those with chronic pain, opioid use disorder or both.

\section{Anticipating Unintended Consequences}

To develop a better drug policy, it is imperative that we understand the unintended consequences of past approaches. Because the liberal prescribing of opioids was and remains an important contributor to opioid-related harms, including overdose, clinical guidelines have been developed in North America to promote evidenceinformed safe and appropriate opioid prescribing for patients with chronic pain (Busse et al. 2017). However, unanticipated consequences of these guidelines have been described, including rapid and potentially harmful tapering practices, dismissal of patients from primary care practices and shifts between the prescribed and non-prescribed environments (Antoniou et al. 2019; Dowell et al. 2019). In recognition of these phenomena, the Centers for Disease Control and Prevention released a statement in 2019 clarifying the intention of their 2016 recommendations (Dowell et al. 2019) and highlighting the serious implications of misapplication of new guidelines and the need for careful communication of how these recommendations should be implemented in clinical practice. Importantly, increasing the availability and funding of multidisciplinary pain care and integrated primary care, mental health services and substance use disorder treatment would fill gaps in the care for people who elect to discontinue opioids. 
Implementing policies that restrict access to prescription opioids requires other interventions to prevent harm to people who take these drugs. These could include expanding harm reduction supports, particularly to populations that are disproportionately represented among fatal opioid doses, including those in rural communities and Indigenous populations and those with a history of incarceration, and using communitybased approaches to develop culturally and contextually appropriate services. In addition, prescription-focused policy changes have the potential to drive users to the non-prescribed opioid market, which is inherently far more dangerous. Therefore, continued availability of a safer supply could potentially prevent deaths associated with non-prescribed synthetic drugs (Canadian Association of People Who Use Drugs 2019). Furthermore, much-sought-after solutions to structural drivers of opioid overdose, such as homelessness and poverty, will require the collective will of multiple levels of government.

Finally, the criminalization of possession of drugs for personal use continues to play an important role in the ongoing overdose crisis for many reasons (Juurlink and Virani 2018), including the harms associated with prosecution and incarceration for possession of controlled substances and the reduced opportunities for medical intervention during an overdose. For example, criminalization of drug use can lead people to use drugs alone, removing the ability for someone to intervene in the event of an overdose. This is highlighted in two recently published Canadian reports where more than half of the fatal opioid-related overdoses occurred when someone was alone at the time of their death (Alberta Health 2019; Public Health Ontario 2019). Furthermore, despite the enactment of Good Samaritan laws that offer legal protection to people who seek emergency help during an overdose (Government of Canada 2019; Haegerich et al. 2014), limitations to the scope of these laws have led to an ongoing fear of arrest and incarceration among people who use drugs (Koester et al. 2017; von Scheel 2018). Therefore, even in circumstances where intervention is possible, criminalization of non-medical opioid use can prevent efficient access to emergency services during an overdose. Although determining the best approach to decriminalization is complex and multifaceted (Jesseman and Payer 2018), there is an urgent need for policy makers to work across sectors to determine opportunities for legislative change that can address the harms associated with criminalization of opioids.

\section{Summary}

We have an opportunity to design policy responses to the current opioid crisis that are informed by the successes and limitations of past approaches and that promote more thoughtful, judicious prescribing to opioid-naïve individuals while avoiding unintended harm to those already using opioids. The end goal of reducing opioid-related harm can only be achieved by broad, multidisciplinary implementation of evidence-informed harm reduction programs, including naloxone distribution (Irvine et al. 2019), supervised consumption sites (Kerr et al. 2017; Marshall et al. 2011; Young and Fairbairn 2018) and safer drug supplies (Canadian Association of People Who Use Drugs 2019; Oviedo-Joekes et al. 2009, 2016; van den Brink et al. 2003). Finally, it is imperative that we undertake policy evaluation and revision when unintended harms are identified and meaningful, consistent dialogue between policy makers and people with lived experience to better understand the emerging needs and priorities of the people affected by the shifting opioid policy environment every day. $\mathrm{HQ}$

\section{Acknowledgements}

We gratefully acknowledge members of the Ontario Drug Policy Research Network's Lived Experience Advisory Group and Dr. Tony Antoniou for their time reviewing and providing valuable input on earlier drafts of the manuscript.

\section{References}

Alberta Health. 2019, July. Opioid-Related Deaths in Alberta in 2017: Review of Medical Examiner Data. Edmonton, AB: Government of Alberta. Retrieved August 6, 2019. <https://open.alberta.ca/dataset/f9912915bd4f-4b57-93bf-2a963cb99038/resource/a2857fb6-6663-491c-b9df686e348bb456/download/070519-me-chart-review-final.pdf>.

Antoniou, T., K. Ala-Leppilampi, D. Shearer, J.A. Parsons, M. Tadrous and T. Gomes. 2019. "Like Being Put on an Ice Floe and Shoved Away": A Qualitative Study of the Impacts of Opioid-Related Policy Changes on People Who Take Opioids. International Journal on Drug Policy 66: 15-22. doi:10.1016/j.drugpo.2019.01.015.

Bohnert, A.S., M. Valenstein, M.J. Blair, D. Ganoczy, J.F. McCarthy, M.A. Ilgen et al. 2011. Association between Opioid Prescribing Patterns and Opioid Overdose-Related Deaths. JAMA 305(13): 1315-21. doi:10.1001/jama.2011.370.

Busse, J.W., S. Craigie, D.N. Juurlink, D.N. Buckley, L. Wang, R.J. Couban et al. 2017. Guideline for Opioid Therapy and Chronic Noncancer Pain. CMAJ 189(18): E659-66. doi:10.1503/cmaj.170363.

Canadian Association of People Who Use Drugs. 2019, February. Safe Supply Concept Document. Retrieved August 6, 2019. <http:// capud.ca/sites/default/files/2019-03/CAPUD\%20safe\%20supply\%20 English\%20March\%203\%202019.pdf>.

Dhalla, I.A., M.M. Mamdani, M.L.A. Sivilotti, A. Kopp, O. Qureshi and D.N. Juurlink. 2009. Prescribing of Opioid Analgesics and Related Mortality before and after the Introduction of Long-Acting Oxycodone. CMAJ 181(12): 891-96. doi:10.1503/cmaj.090784.

Dowell, D., T. Haegerich and R. Chou. 2016. CDC Guideline for Prescribing Opioids for Chronic Pain-United States, 2016. JAMA 315(15): 1624-45. doi:10.1001/jama.2016.1464.

Dowell, D., T. Haegerich and R. Chou. 2019. No Shortcuts to Safer Opioid Prescribing. New England Journal of Medicine 380(24): 2285-87. doi:10.1056/NEJMp1904190.

Dyer, O. 2016. Ontario Plans to Stop Funding High Dose Opioids. BMJ 354: i4300. doi:10.1136/bmj.i4300.

Furlan, A.D., P. MacDougall, D. Pellerin, K. Shaw, D. Spitzig, G. Wilson et al. 2014. Overview of Four Prescription Monitoring/ Review Programs in Canada. Pain Research and Management 19(2): 102-106. doi:10.1155/2014/634171. 
Gomes, T., M.M. Mamdani, I.A. Dhalla, J.M. Paterson and D.N. Juurlink. 2011. Opioid Dose and Drug-Related Mortality in Patients with Nonmalignant Pain. Archives of Internal Medicine 171(7): 686-91. doi:10.1001/archinternmed.2011.117.

Gomes, T., S. Greaves, D. Martins, D. Bandola, M. Tadrous, S. Singh et al. 2017a. Latest Trends in Opioid-Related Deaths in Ontario: 1991 to 2015. Toronto, ON: Ontario Drug Policy Research Network. Retrieved August 6, 2019. <https://odprn.ca/wp-content/uploads/2017/04/ ODPRN-Report_Latest-trends-in-opioid-related-deaths.pdf>.

Gomes, T., A. Mastorakos, J.M. Paterson, I. Sketris, P. Caetano, S. Greaves et al. 2017b. Changes in the Dispensing of Opioid Medications in Canada following the Introduction of a TamperDeterrent Formulation of Long-Acting Oxycodone: A Time Series Analysis. CMAJ Open 5(4): E800-807. doi:10.9778/cmajo.20170104.

Gomes, T., S. Greaves, M. Tadrous, M.M. Mamdani, J.M. Paterson and D.N. Juurlink. 2018a. Measuring the Burden of Opioid-Related Mortality in Ontario, Canada. Journal of Addiction Medicine 12(5): 418-19. doi:10.1097/ADM.0000000000000412.

Gomes, T., S. Jain, J.M. Paterson, I. Sketris, P. Caetano, D. Henry, the Canadian Network for Observational Drug Effect Studies (CNODES) Investigators. 2018b. Trends and Uptake of New Formulations of Controlled-Release Oxycodone in Canada. Pharmacoepidemiology and Drug Safety 27(5): 520-25. doi:10.1002/pds.4390.

Government of Canada. 2018. Regulations Amending the Food and Drug Regulations (Opioids): SOR/2018-77. Retrieved July 18, 2019. <http://gazette.gc.ca/rp-pr/p2/2018/2018-05-02/html/ sor-dors77-eng.html>.

Government of Canada. 2019. About the Good Samaritan Drug Overdose Act. Retrieved July 18, 2019. <https://www.canada.ca/ en/health-canada/services/substance-use/problematic-prescriptiondrug-use/opioids/about-good-samaritan-drug-overdose-act.html>.

Government of Ontario. 2015. Safeguarding Our Communities Act (Patch for Patch Return Policy), 2015, S.O. 2015, c. 33. Retrieved July 18, 2019. <https://www.ontario.ca/laws/statute/15s33>.

Haegerich, T.M., L.J. Paulozzi, B.J. Manns and C.M. Jones. 2014. What We Know, and Don't Know, about the Impact of State Policy and Systems-Level Interventions on Prescription Drug Overdose. Drug and Alcohol Dependence 145: 34-47. doi:10.1016/j. drugalcdep.2014.10.001.

Irvine, M.A., M. Kuo, J.A. Buxton, R. Balshaw, M. Otterstatter, L. Macdougall et al. 2019. Modelling the Combined Impact of Interventions in Averting Deaths during a Synthetic-Opioid Overdose Epidemic. Addiction 114(9): 1602-13. doi:10.1111/add.14664.

Jesseman, R. and D. Payer. 2018. Decriminalization: Options and Evidence. Ottawa, ON: Canadian Centre on Substance Use and Addiction. Retrieved July 18, 2019. <https:/www.ccsa.ca/sites/default/ files/2019-04/CCSA-Decriminalization-Controlled-SubstancesPolicy-Brief-2018-en.pdf>.

Juurlink, D. and H. Virani. 2018, April 15. The Case for Decriminalizing Drugs. Toronto Star. Retrieved August 6, 2019. <https://www.thestar. com/opinion/contributors/2018/04/15/the-case-for-decriminalizingdrugs.html>.

Kerr, T., S. Mitra, M.C. Kennedy and R. McNeil. 2017. Supervised Injection Facilities in Canada: Past, Present, and Future. Harm Reduction Journal 14(1): 28. doi:10.1186/s12954-017-0154-1.

Koester, S., S.R. Mueller, L. Raville, S. Langegger and I.A. Binswanger. 2017. Why Are Some People Who Have Received Overdose Education and Naloxone Reticent to Call Emergency Medical Services in the Event of Overdose? International Journal on Drug Policy 48: 115-24. doi:10.1016/j.drugpo.2017.06.008.
Marshall, B.D.L., M.-J. Milloy, E. Wood, J.S.G. Montaner and T. Kerr. 2011. Reduction in Overdose Mortality after the Opening of North America's First Medically Supervised Safer Injecting Facility: A Retrospective Population-Based Study. Lancet 377(9775): 1429-37. doi:10.1016/S0140-6736(10)62353-7.

Meier, B. 2007, May 10. In Guilty Plea, OxyContin Maker to Pay $\$ 600$ Million. New York Times. Retrieved August 6, 2019. <https:// www.nytimes.com/2007/05/10/business/11drug-web.html>.

Miller, A. 2013. FDA Ban of Generic Oxycodone Calls into Question Health Canada's Approval. CMAJ 185(9): E381-82. doi:10.1503/ cmaj.109-4476.

Ontario Agency for Health Promotion and Protection (Public Health Ontario); Office of the Chief Coroner; Ontario Forensic Pathology Service; Ontario Drug Policy Research Network. 2019, June. Opioid Mortality Surveillance Report: Analysis of Opioid-Related Deaths in Ontario July 2017-June 2018. Toronto, ON: Queen's Printer for Ontario. Retrieved July 18, 2019. <https://www.publichealthontario. $\mathrm{ca} /$-/media/documents/opioid-mortality-surveillance-report.pdf>

Ontario College of Pharmacists. 2016. Patch-For-Patch Fentanyl Return Program: Fact Sheet. Retrieved December 15, 2017. <http:// www.ocpinfo.com/regulations-standards/policies-guidelines/Patch_ For_Patch_Fentanyl_Return_Fact_Sheet/>.

Ontario Drug Policy Research Network. 2019. Ontario Prescription Opioid Tool. Retrieved July 18, 2019. <https://odprn.ca/ontarioopioid-drug-observatory/ontario-prescription-opioid-tool/>.

Ontario Ministry of Health and Long-Term Care. 2017. Narcotics Monitoring System. Retrieved July 18, 2019. <http://www.health.gov. on.ca/en/pro/programs/drugs/ons/monitoring_system.aspx>.

Oviedo-Joekes, E., S. Brissette, D.C. Marsh, P. Lauzon, D. Guh, A. Anis et al. 2009. Diacetylmorphine Versus Methadone for the Treatment of Opioid Addiction. New England Journal of Medicine 361(8): 777-86. doi:10.1056/NEJMoa0810635.

Oviedo-Joekes, E., D. Guh, S. Brissette, K. Marchand, S. MacDonald, K. Lock et al. 2016. Hydromorphone Compared with Diacetylmorphine for Long-Term Opioid Dependence: A Randomized Clinical Trial. JAMA Psychiatry 73(5): 447-55. doi:10.1001/ jamapsychiatry.2016.0109.

Park, T.W., R. Saitz, D. Ganoczy, M.A. Ilgen and A.S. Bohnert. 2015. Benzodiazepine Prescribing Patterns and Deaths from Drug Overdose among US Veterans Receiving Opioid Analgesics: Case-Cohort Study. BMJ 350: h2698. doi:10.1136/bmj.h2698.

Persaud, N. 2014. Questionable Content of an Industry-Supported Medical School Lecture Series: A Case Study. Journal of Medical Ethics 40(6): 414-18. doi:10.1136/medethics-2013-101343.

Public Health Ontario. 2019. Interactive Opioid Tool. Retrieved July 18, 2019. <https:/www.publichealthontario.ca/en/data-and-analysis/ substance-use/interactive-opioid-tool>.

Special Advisory Committee on the Epidemic of Opioid Overdoses. 2019, September. National Report: Apparent Opioid-Related Deaths in Canada (January 2016 to December 2018). Ottawa, ON: Public Health Agency of Canada. Retrieved July 28, 2019. <https://health-infobase. canada.ca/datalab/national-surveillance-opioid-mortality.html>.

Statistics Canada. 2019, May. Changes in Life Expectancy by Selected Causes of Death, 2017. Retrieved July 18, 2019. <https://www150. statcan.gc.ca/n1/daily-quotidien/190530/dq190530d-eng.htm>.

U.S. Food and Drug Administration. 2007, May 8. FDA Announces Results of Investigation into Illegal Promotion of OxyContin by the Purdue Frederick Company, Inc. Company Misrepresented Prescription Pain Reliever to Health Care Professionals. Retrieved July 18, 2019. $<$ https://www.medicinenet.com/script/main/art.asp?articlekey=81038>. 
van den Brink, W., V.M. Hendriks, P. Blanken, M.W.J. Koeter B.J. van Zwieten and J.M. van Ree. 2003. Medical Prescription of Heroin to Treatment Resistant Heroin Addicts: Two Randomised Controlled Trials. BMJ 327(7410): 310. doi:10.1136/bmj.327.7410.310.

Van Zee, A. 2009. The Promotion and Marketing of Oxycontin: Commercial Triumph, Public Health Tragedy. American Journal of Public Health 99(2): 221-27. doi:10.2105/AJPH.2007.131714.

von Scheel, E. 2018, August 18. Despite "Good Samaritan” Law, Many Drug Users Too Scared of Arrest to Report Overdoses. $C B C$ News. Retrieved August 6, 2019. <https://www.cbc.ca/ news/politics/good-samaritan-drug-overdose-fentanyl-politicsparliament-1.4786094>.

Vowles, K.E., M.L. McEntee, P.S. Julnes, T. Frohe, J.P. Ney and D.N. van der Goes. 2015. Rates of Opioid Misuse, Abuse, and Addiction in Chronic Pain: A Systematic Review and Data Synthesis. Pain 156(4): 569-76. doi:10.1097/01.j.pain.0000460357.01998.f1.
Young, S. and N. Fairbairn. 2018. Expanding Supervised Injection Facilities across Canada: Lessons from the Vancouver Experience. Canadian Journal of Public Health 109(2): 227-30. doi:10.17269/ s41997-018-0089-7.

\section{About the Authors}

Tara Gomes, PhD, is an epidemiologist and scientist at St. Michael's Hospital and ICES in Toronto, ON. She holds a Tier 2 Canada Research Chair in Drug Policy Research and Evaluation. She may be contacted by e-mail at gomest@smh.ca.

David N. Juurlink, MD, PhD, is an internal medicine physician at Sunnybrook Health Sciences Centre and a scientist at ICES

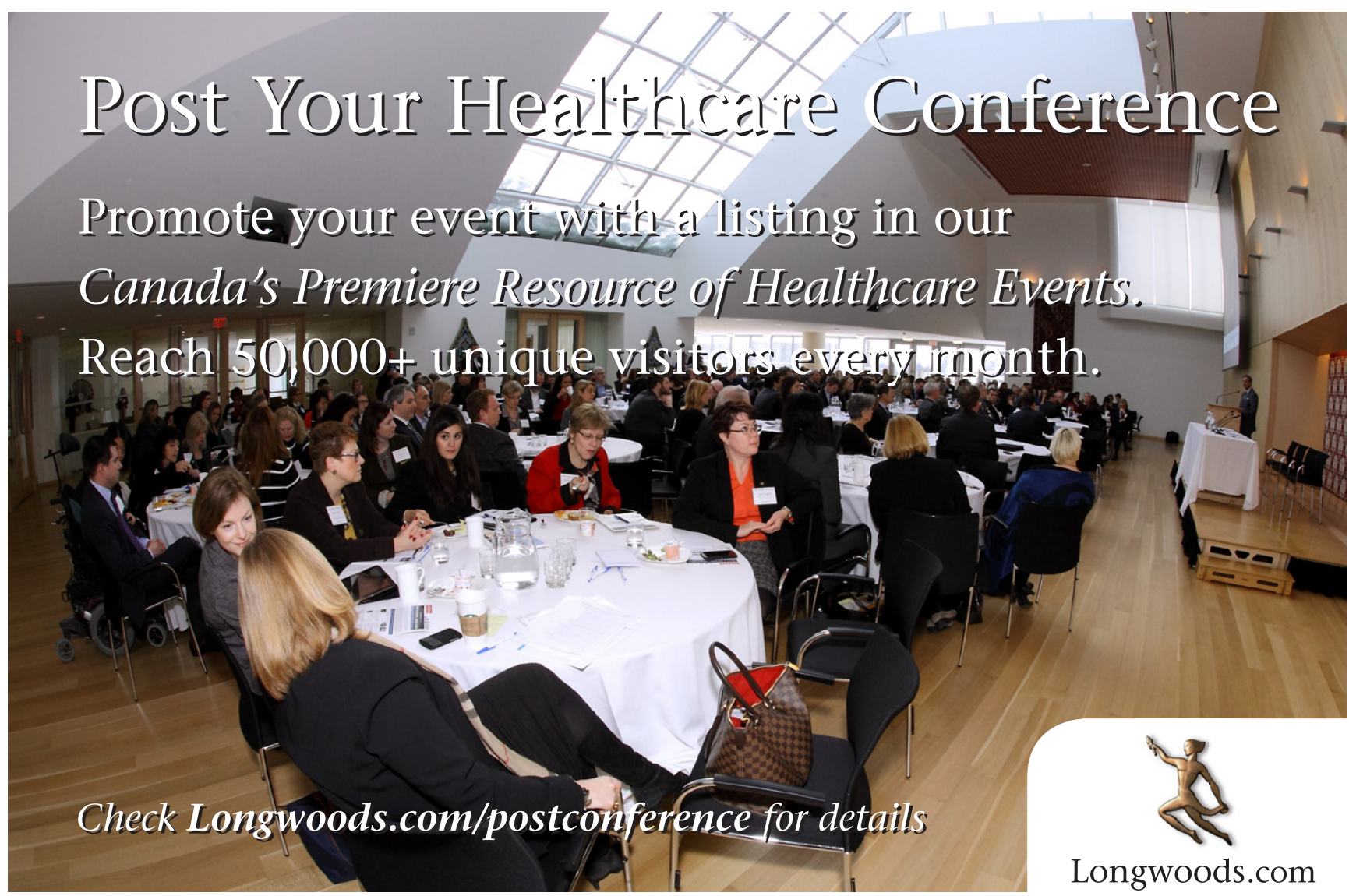

